\title{
ANALISIS SALURAN PEMASARAN MANGGIS (Suatu Kasus di Desa Kalijaya Kecamatan Banjaranyar Kabupaten Ciamis)
}

\author{
ANALYSIS OF MANGOSTEEN MARKETING CHANNELS \\ (A Case of Village Kalijaya Banjaranyar District of Ciamis Regency)
}

\author{
FITRI KARTIKASARI ${ }^{1}$, TRISNA INSAN NOOR $^{2}$,AGUS YUNIAWAN ISYANTO ${ }^{1}$ \\ ${ }^{1}$ Fakultas Pertanian Universitas Galuh \\ ${ }^{2}$ Fakultas Pertanian Universitas Padjajaran \\ *Email: fitrikartikasari8773@gmail.com
}

\begin{abstract}
ABSTRAK
Penelitian ini bertujuan untuk mengetahui: (1) Saluran pemasaran manggis di Desa Kalijaya Kecamatan Banjaranyar Kabupaten Ciamis; (2) Besarnya biaya dan keuntungan pemasaran; (3) Besarnya marjin pemasaran manggis pada setiap tingkatan lembaganya; dan (4) Besarnya bagian harga (farmer's share) yang diterima petani keseluruhan harga yang dibayar oleh konsumen. Jenis penelitian yang digunakan dalam penelitian ini adalah studi kasus. Sampel penelitian ini terdiri atas 54 petani, 2 pedagang pengumpul, 1 pedagang besar dan 2 konsumen industri. Hasil penelitian menunjukan: (1) Ada dua saluran pemasaran; (2) Biaya pemasaran pada saluran pemasaran I sebesar $\mathrm{Rp} 75,00$ per $\mathrm{kg}$ dan saluran pemasaran II sebesar Rp 324,53 per kg. Keuntungan pemasaran pada saluran pemasaran I sebesar Rp 235,00 per kg dan saluran pemasaran II sebesar Rp 645,47 per kg; (3) Marjin pemasaran pada saluran pemasaran I sebesar Rp 310,00 per $\mathrm{kg}$ dan saluran pemasaran II sebesar Rp 970,00 per kg; dan (4) Farmer's share pada saluran pemasaran I 96,03\% dan saluran pemasaran II $88,12 \%$.
\end{abstract}

Kata kunci: Pemasaran, manggis, farmer's share

\begin{abstract}
This study aims to determine: (1) Mangosteen marketing channel in Kalijaya Village, Banjaranyar District, Ciamis Regency; (2) Marketing costs and profit; (3) Mangosteen marketing margin at each marketing institution; and (4) Farmer's share. This type of research used in this research is a case study. The research sample consisted of 54 farmers, 2 collecting traders, 1 large trader and 2 industrial consumers. The results showed: (1) There are two marketing channels; (2) Marketing costs in marketing channel I is Rp 75.00 per $\mathrm{kg}$ and marketing channel II is Rp 324.53 per kg. Marketing profits in marketing channel I amounted to $R p 235.00$ per $\mathrm{kg}$ and marketing channel II amounted to Rp 645.47 per kg; (3) Marketing margin in marketing channel I is Rp 310.00 per kg and marketing channel II is Rp 970.00 per kg; and (4) Farmer's share in marketing channel I 96.03\% and marketing channel II $88.12 \%$.
\end{abstract}

Keywords: Marketing, mangosteen, farmer's share

\section{PENDAHULUAN}

Pertanian merupakan sektor kedua paling berpengaruh terhadap pertumbuhan ekonomi di Indonesia setelah industri pengolahan. Bila dibandingkan dengan triwulan sebelumnya, sektor pertanian menjadi sektor yang mempunyai pertumbuhan tertinggi, yaitu sebesar 8,44 persen. Peningkatan ini diperoleh dari meningkatnya produksi sejumlah komoditas tanaman perkebunan dan hortikultura (Haris, 2017). 
Hortikultura secara luas memiliki makna tidak hanya digunakan untuk tanaman kebun saja, melainkan untuk semua jenis tanaman yang dibudidayakan. Salah satu komoditas hortikultura adalah manggis. Salah satu sifat dari produk hortikultura adalah mudah rusak atau perishable (Туо, 2017).

Komoditas unggulan buah-buahan yang khas dari kecamatan Banjaranyar salah satunya adalah buah manggis, Keistimewaan buah manggis di Kecamatan Banjaranyar dibandingkan dengan buah manggis lainnya yaitu mempunyai rasa lebih manis dan sedikit masam (manis segar) dibandingkan dengan buah manggis pada umumnya.

Penelitian ini dilaksanakan dnegan tujuan penelitian untuk mengetahui: (1) Saluran pemasaran manggis di Desa Kalijaya Kecamatan Banjaranyar Kabupaten Ciamis, (2) Besarnya biaya dan keuntungan pemasaran, (3) Besarnya marjin pemasaran manggis untuk setiap tingkatan lembaganya, dan (4) Besarnya bagian harga yang diterima petani dari keseluruhan harga yang dibayar oleh konsumen (farmer's share).

\section{METODE PENELITIAN}

Penelitian dilaksanakan dengan menggunakan metode survei. Menurut
Nazir (2003), metode survai menggunakan campuran dari teknik yang melingkupi sampel yang cukup besar sampai teknik pengamatan yang kurang baku dengan sampel kecil dari kualitatif, ataupun pengkajian yang cukup mendalam perihal suatu fenomena. Metode survai dilakukan di lapangan, karena desain untuk penelitian survai sangat bergantung dari pemilihan responden, pemilihan alat pengumpulan data, prosedur-prosedur yang dilaksanakan serta kondisi di lapangan.

Data yang digunakan dalam penelitian ini meliputi data primer dan data sekunder. Data primer didapat dari responden petani manggis melalui wawancara langsung dengan menggunakan kuesioner sebagai alat bantu yang sudah dipersiapkan sebelumnya. Sedangkan data sekunder diperoleh dari dinas atau intansi yang terkait dengan penelitian ini dan dari pengkajian kepustakaan.

Desa Kalijaya Kecamatan Banjaranyar dipilih secara sengaja (purposive sampling) sebagai lokasi penelitian dengan pertimbangan lokasi ini termasuk daerah penghasil manggis yang cukup besar.

Jumlah petani manggis di Desa Kalijaya adalah 54 orang yang diambil seluruhnya sebagai sampel penelitian atau dilaksanakan sensus. Sampel pelaku 
pemasaran diambil dengan menggunakan snowball sampling.

Untuk mengetahui pola saluran pemasaran manggis di Desa Kalijaya Kecamatan Banjaranyar Kabupaten Ciamis. dengan menggunakan metode deskriptif. Sedangkan untuk mengetahui biaya pemasaran dan marjin pemasaran di tingkat lembaga dalam saluran pemasaran digunakan alat analisis biaya dan marjin pemasaran (cost margin analysis) yaitu dengan menghitung besarnya biaya, keuntungan dan marjin pemasaran pada tiap lembaga perantara pada berbagai saluran pemasaran.

Biaya pemasaran adalah biaya yang dikeluarkann untuk memasarkan suatu komoditi dari produsen ke konsumen. Menurut Handayani dan Nurlaila (2011), secara sistematis biaya pemasaran dapat dirumuskan sebagai berikut:

$\mathrm{Bp}=\mathrm{Bp} 1+\mathrm{Bp} 2+\mathrm{Bp} 3+\ldots \ldots+\mathrm{Bpn}$

Keterangan:

Bp : Biaya pemasaran

Bp1,2,3...n : Biaya pemasaran tiap lembaga pemasaran

\section{1,2,3 ...n : Jumlah lembaga}

Keuntungan pemasaran adalah

penjumlahan dari keuntungan yang diterima oleh setiap lembaga pemasaran. Keuntungan pemasaran dapat dirumuskan sebagai berikut (Handayani dan Nurlaila, 2011):

$$
\mathrm{Kp}=\mathrm{Kp} 1+\mathrm{Kp} 2+\mathrm{Kp} 3+\ldots \ldots . .+\mathrm{Kpn}
$$

Dimana:

Kp : Keuntungan pemasaran

Marjin pemasaran adalah selisih harga di tingkat produsen dan tingkat konsumen akhir. Menurut Handayani dan Nurlaila (2011), marjin pemasaran dapat dirumuskan sebagai berikut:

$$
\mathbf{M}=\mathbf{P r}-\mathbf{P f}
$$

Dimana:

Pr : Harga di tingkat konsumen

Pf : Harga di tingkat produsen

$\mathrm{M}$ : Marjin pemasaran

Farmer's Share menurut besarnya bagian harga bagi petani dari harga jual, dan dihitung dengan rumus sebagai berikut:

$F S=\frac{\mathrm{pf}}{\mathrm{pr}} \times 100 \%$

Dimana:

FS : bagian harga yang diterima produsen (Farmer's Share)

Pf : harga di tingkat petani $(\mathrm{Rp} / \mathrm{Kg})$

$\mathrm{Pr}$ : harga di tingkat lembaga pemasaran (Rp/Kg)

\section{HASIL DAN PEMBAHASAN}

\section{Saluran Pemasaran}

Berdasarkan hasil penelitian yang telah dilaksanakan dapat diuraikan mengenai pola saluran pemasaran manggis di Desa Kalijaya Kecamatan Banjaranyar Kabupaten Ciamis. Pengumpulan data untuk mengetahui berbagai hasil pemasaran manggis yang digunakan, diperoleh dengan cara penelusuran jalur pemasaran manggis mulai dari petani, 
lembaga pemasaran, sampai konsumen. Saluran pemasaran I banyak digunakan petani manggis yaitu 34 orang (37.03\%) dan saluran pemasaran II sebanyak 20 orang (59.25\%). Konsumen dalam hal ini adalah para konsumen yang membeli manggis yang masih berada dalam batas Desa Kalijaya Kecamatan Banjaranyar Kabupaten Ciamis, sebab penelitian manggis ini dibatasi hanya di Desa Kalijaya.

\section{Kegiatan di Tingkat Pedagang Pengumpul}

Ada dua orang pedagang pengumpul dalam penelitian ini yang berada di Desa Kalijaya. Para pedagang pengumpul tersebut mendapatkan manggis dengan cara membeli dari petani manggis. Pedagang pengumpul menerima manggis dari petani tiap harinya sekitar $125 \mathrm{~kg}$. Setelah mendapat manggis dari petani, pedagang pengumpul mengemas manggis dengan peti dan plastik, setiap petinya berisi manggis sebanyak $10 \mathrm{~kg}$. Pedagang pengumpul dalam menyalurkan lagi manggis ke pedagang besar atau konsumen industri. Semua pedagang pengumpul itu menjalankan usaha dagangnya dengan menggunakan modal sendiri.
Tabel 1. Rata-rata Biaya Pemasaran Manggis di Tingkat Pedagang Pengumpul pada Saluran I

\begin{tabular}{clcc}
\hline \multirow{2}{*}{ No } & \multirow{2}{*}{ Jenis Biaya } & \multicolumn{2}{c}{ Besarnya Biaya } \\
\cline { 3 - 4 } & & Rp/kg & Persentase (\%) \\
\hline 1 & Transportasi & 5,00 & 6,67 \\
2 & Kemasan & 50,00 & 66,67 \\
3 & Retribusi & 20,00 & 26,66 \\
\hline & Jumlah & $\mathbf{7 5 , 0 0}$ & $\mathbf{1 0 0 , 0 0}$ \\
\hline
\end{tabular}

Tabel 2 Rata-rata Biaya Pemasaran Manggis di Tingkat Pedagang Besar pada Saluran II

\begin{tabular}{clrr}
\hline \multirow{2}{*}{ No } & \multirow{2}{*}{ Jenis Biaya } & \multicolumn{2}{c}{ Besarnya Biaya } \\
\cline { 3 - 4 } & & Rp/kg & Persentase (\%) \\
\hline 1 & Transportasi & 13,33 & 14,28 \\
2 & Kemasan & 0,00 & 53,58 \\
3 & Retribusi & 30,00 & 32,14 \\
\hline & Jumlah & $\mathbf{9 3 , 3 3}$ & $\mathbf{1 0 0 , 0 0}$ \\
\hline
\end{tabular}

\section{Kegiatan di Tingkat Pedagang Besar}

Pedagang besar ini mendapatkan manggis dari pedagang pengumpul yang berada di Desa Kalijaya, kemudian memasarkan manggis tersebut ke konsumen industri yang berada di Kecamatan Puspahiang. Konsumen di Puspahiang ini merupakan salah satu konsumen industri terbesar yang berada di Kecamatan Puspahiang. Konsumen Industri ini mendapatkan manggis dari pedagang besar tiap harinya sekitar 1 ton. Setelah mendapatkan manggis, pedagang besar mengemasnya terlebih dahulu dengan plastik dan dimasukkan ke dalam peti yang sudah ada labelnya sebelum dijual. Pedagang besar mengemas manggis $10 \mathrm{~kg}$ tiap petinya. Dalam memasarkan manggis ke konsumen besar ini, pedagang besar selain mengeluarkan biaya untuk pengemasan, pedagang besar juga 
mengeluarkan biaya untuk transportasi, bongkar muat, dan sopir. Penjualan ke Puspahiang ini dilakukan setiap tujuh hari sekali. Dalam satu kali transaksi penjualan dapat mencapai penjualan sekitar tiga ton. Pedagang besar dalam menjalankan usahanya ini menggunakan modal sendiri.

Tabel 3. Rata-rata Biaya Pemasaran Manggis di Tingkat Pedagang Besar

\begin{tabular}{clrr}
\hline \multirow{2}{*}{ No } & \multirow{2}{*}{ Jenis Biaya } & \multicolumn{2}{c}{ Besarnya Biaya } \\
\cline { 3 - 4 } & & Rp/Kg & Persentase (\%) \\
\hline 1 & Transportasi & 102,60 & 44,37 \\
2 & Muat & 2,60 & 1,12 \\
3 & Kemasan & 60,00 & 25,96 \\
4 & Retribusi & & 28,55 \\
& & 66,00 & \\
\hline & Jumlah & $\mathbf{2 3 1 , 2 0}$ & $\mathbf{1 0 0 , 0 0}$ \\
\hline
\end{tabular}

\section{Kegiatan di Tingkat Konsumen Industri}

Konsumen industri dalam penelitian ini ada satu orang yang terdapat di Desa Puspahiang. Konsumen industri ini mendapat manggis dari para pedagang besar. Konsumen industri mendapatkan manggis dari pedagang besar tiap tujuh hari sekali dengan jumlah sekitar 1 ton.

Cara pembelian manggis oleh konsumen industri yaitu dengan cara mendatangi pedagang pengumpul dan pedagang besar. Manggis di pedagang pengumpul seharga $\mathrm{Rp} 7.500,00$ sampai 7.200 per kg. Konsumen industri membeli manggis di pedagang besar seharga $\mathrm{Rp}$ 7.570,00 dibayar dengan cara tunai.

\section{Biaya, Marjin dan Keuntungan Pemasaran}

Analisis data yang dilakukan dalam penelitian pemasaran manggis ini meliputi saluran pemasaran, biaya pemasaran, keuntungan pemasaran, marjin pemasaran dan farmer's share (Tabel 4).

Tabel 4. Saluran pemasaran, biaya pemasaran, keuntungan pemasaran, marjin pemasaran dan farmer's share

\begin{tabular}{|c|c|c|c|}
\hline No & Lembaga Pemasaran & $\begin{array}{c}\text { Saluran I } \\
\text { Satuan }(\mathrm{Rp} / \mathrm{Kg})\end{array}$ & $\begin{array}{c}\text { Saluran II } \\
\text { Satuan }(\mathrm{Rp} / \mathrm{Kg})\end{array}$ \\
\hline 1 & Petani & & \\
\hline & Harga Jual & $7.500,00$ & $7.200,00$ \\
\hline \multirow[t]{6}{*}{2} & Pedagang Pengumpul & & \\
\hline & Harga Beli & $7.500,00$ & $7.200,00$ \\
\hline & Harga Jual & $7.810,00$ & $7.570,00$ \\
\hline & Biaya & 75,00 & 93,33 \\
\hline & Keuntungan & 235,00 & 276,67 \\
\hline & Marjin & 310,00 & 370,00 \\
\hline \multirow[t]{6}{*}{3} & Pedagang Besar & & \\
\hline & Harga Beli & & 7.570 \\
\hline & Harga Jual & & 8.170 \\
\hline & Biaya & & 231.2 \\
\hline & Keuntungan & & 368,8 \\
\hline & Marjin & & 600,00 \\
\hline \multirow[t]{2}{*}{4} & Konsumen Industri & & \\
\hline & Harga Beli & 7.810 & 8.170 \\
\hline \multicolumn{2}{|c|}{ Biaya Total } & 75,00 & $\mathbf{3 2 4 , 5 3}$ \\
\hline \multicolumn{2}{|c|}{ Keuntungan Total } & 235,00 & 645,47 \\
\hline \multicolumn{2}{|c|}{ Marjin Total } & 310,00 & 970,00 \\
\hline \multicolumn{2}{|c|}{ Farmer's share } & $96,03 \%$ & $88,12 \%$ \\
\hline
\end{tabular}


Tabel 4 menunjukkan bahwa marjin pemasaran pada Saluran I sebesar Rp 310, sedangkan pada Saluran II sebesar Rp 970.

Biaya pemasaran pada Saluran I sebesar Rp 75, sedangkan pada Saluran II sebesar Rp 324,53.

Keuntungan pemasaran pada Saluran I sebesar Rp 235, sedangkan pada Saluran II sebesar Rp 645,47.

Farmer's share pada Saluran I sebesar 96,03\%, sedangkan pada Saluran Pemasaran II sebesar $88,12 \%$.

\section{KESIMPULAN DAN SARAN}

\section{Kesimpulan}

Berdasarkan hasil penelitian pemasaran Manggis di Kalijaya Kecamatan Banjaranyar Kabupaten Ciamis dapat ditarik kesimpulan sebagai berikut:

1. Dalam pemasaran Manggis di Kalijaya Kecamatan Banjaranyar Kabupaten Ciamis terdapat dua saluran pemasaran yaitu : (1) Petani $\rightarrow$ Pedagang Pengumpul $\rightarrow$ Konsumen Industri (2) Petani $\rightarrow$ Pedagang Pengumpul $\rightarrow$ Pedagang Besar $\rightarrow$ Konsumen Industri

2. Biaya pemasaran pada saluran II lebih besar dari saluran I.

3. Marjin pemasaran pada saluran pemasaran II lebih besar dari saluran pemasaran I
4. Farmer's share atau bagian harga yang diterima petani pada saluran pemasaran I lebih besar dari saluran II.

\section{Saran}

Berdasarkan pada kesimpulan yang telah dihasilkan dari penelitian ini, maka dapat dikemukakan beberapa saran sebagai berikut:

1) Petani disarankan untuk memilih saluran I karena bagian harga yang diterima petani lebih besar $(96,03 \%)$ dibandingkan pada saluran II $(88,12 \%)$.

2) Pemerintah diharapkan dapat membantu pengelolaan manggis oleh para petani dengan melakukan teknik pembelajaran tambahan seperti penyuluhan terhadap petani agar petani dapat meningkatkan sumber daya manusia dan sumber daya alam. Selain itu petani dapat menyelesaikan permasalahannya dengan baik.

\section{DAFTAR PUSTAKA}

Handayani, S.M dan I. Nurlaila. (2011). Analisis Pemasaran Susu Segar di Kabupaten Klaten. Jurnal Sains Peternakan, 9(1):

Nazir, M. 2003. Metode Penelitian. Cetakan Keempat, Jakarta: Ghalia Indonesia.

Haris, P. 2017. Sektor Pertanian dan Citra Indonesia di Mata Dunia. Jakarrta Tyo, 2017. Pengertian, jenis dan Manfaat Tanaman Hortikultura. Balubu. 